\title{
Theranostics with Hybrid Liposomes in an Orthotopic Graft Model Mice of Breast Cancer
}

\author{
HIDEAKI ICHIHARA, MASAKI OKUMURA, KENTA TSUJIMURA and YOKO MATSUMOTO
}

Division of Applied Life Science, Graduate School of Engineering, Sojo University, Kumamoto, Japan

\begin{abstract}
Background/Aim: This study aimed to elucidate the therapeutic effects of hybrid liposomes $(H L)$ composed of L- $\alpha$-dimyristylphosphatidylcholine (DMPC) and polyoxyethylene [25] dodecyl ether $\left(\mathrm{C}_{12}(E O)_{25}\right)$ and the ability of HL-containing fluorescent probe to detect cancer in orthotopic graft model mice of breast cancer (MDA-MB453). Materials and Methods: HL composed of $90 \mathrm{~mol} \%$

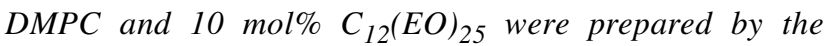
sonication method. Anti-tumor activities of $H L$ were investigated in vivo using orthotopic graft-bearing mice of MDA-MB-453 cells. Results: With regard to the therapeutic effects of HL for breast cancer, HL inhibited the growth of MDA-MB-453 cells and induced apoptosis. Intravenous administration of $H L$ resulted in a remarkable reduction of relative tumor weight in orthotopic graft model mice of breast cancer. The TUNEL assay revealed that this effect was due to induction of apoptosis. With regard to detection (diagnosis) of breast cancer, enhanced accumulation of $H L$ carrying a fluorescence probe (Indocyanine green; ICG) was observed for MDA-MB-453 cells, although no accumulation of HL/ICG was obtained for normal breast cells. Enhanced accumulation of HL/ICG into the tumor of orthotopic graft model mice of breast cancer was observed. Conclusion: $H L$ and HL/ICG could be theranostic targets since they showed therapeutic effects and ability to detect (diagnose) cancer in an orthotopic graft model mouse of breast cancer (MDA$M B-453)$.
\end{abstract}

Breast cancer is one of the leading causes of cancer-related mortality (1). Early detection of breast cancer is essential to extend the survival of patients. Breast cancer could be

Correspondence to: Hideaki Ichihara, Ph.D., Division of Applied Life Science, Graduate School of Engineering, Sojo University, 422-1, Ikeda, Nishi-ku, Kumamoto, 860-0082, Japan. Tel: +81 963265108, Fax: +81 963261331, e-mail: hideaki@life.sojo-u.ac.jp

Key Words: Hybrid liposome, theranostics, breast cancer, apoptosis, chemotherapy, cancer detection. detected by medical imaging tests such as mammography with X-ray, ultrasound imaging and magnetic resonance imaging (MRI). However, mammography and MRI expose patients to the risks associated with radiation and contrast medium, respectively. Breast cancer can be mainly treated by surgical resection, chemotherapy, and radiation therapy. Surgical resection of breast cancer is curative when cancer is limited in a primary area without metastasis. However, surgical resection of the cancer is often accompanied with a removal of healthy tissue during an operation. Chemotherapy with anticancer drugs for the whole body is one of the most widely used treatments for breast cancer. Paclitaxel has been used as chemotherapy for breast cancer (2). Adjuvant systemic therapy of the combination of 5-fluorouracil, epirubicin, cyclophosphamide, adriamycin, and methotrexate is used for the treatment of breast cancer (3). However, most anticancer drugs are accompanied with severe side-effects. Molecular-targeted therapy for tumors has recently attracted attention in connection with reducing the toxicity of anticancer drugs. The human epidermal growth factor receptor (HER-2) is overexpressed in $30 \%$ of patients with breast cancer (4), and therefore the anti-HER-2 antibody (trastuzumab) targeting HER-2 has been developed (5-7). However, trastuzumab is effective only in patients expressing HER-2 (7-8), but this has also side-effects (8). So, drugs without side-effects are necessary to lead to high Quality of Life (QOL) of patients.

Theranostics is a treatment strategy that combines therapeutics with diagnostics. Ideal theranostics for cancer should have the following advantages: (a) the ability for selective accumulation in the cancer tissue, (b) ability to selectively deliver effective therapeutic action, and (c) be safe and non-toxic products. Indocyanine green (ICG) is a fluorescent probe that has been widely used in the biomedical field (8-10). ICG has the attractive properties of very low toxicity and high absorptance in a wavelength range of 600-900 $\mathrm{nm}$ (11), which is a transparent wavelength for biological tissues $(8-10,12)$. A carrier containing ICG as a fluorescent probe that has high selectivity for cancer will provide the possibility of the detection of cancer. 
Hybrid liposomes (HL) composed of vesicular and micellar molecules can be prepared simply by sonication of those molecules in a buffer solution without contamination with organic solvent (13-14). Therapeutic effects of an anticancer drug, 1,3-bis(2-chloroethyl)-1-nitrosourea (BCNU), encapsulated into hybrid liposomes composed of L- $\alpha$-dimyristoylphosphatidylcholine (DMPC) and polyoxyethylene [20] sorbitan monolaurate (Tween 20) have been observed in rat models of meningeal gliomatosis in vivo (15). On the other hand, HL composed of DMPC and polyoxyethylenedodecyl ether without any anticancer drug have inhibited the growth of various types of tumor cells and induced apoptosis in vitro (16-18) and in vivo (19-21). Following approval of the Bioethics Committee, administration of HL without anticancer drugs to patients with lymphoma showed therapeutic effects (22). In addition, long-term accumulation of HL including ICG into the tumor in xenograft model mice of colon cancer has also been reported (23). Furthermore, therapeutic effects of HL without any drugs in a xenograft model mice of colon cancer have also been revealed (23). However, therapeutic effects and accumulation of HL into the tumor of an orthotopic graft model mouse of HER2-negative breast cancer have not yet been elucidated.

This study aimed to demonstrate the therapeutic effects of $\mathrm{HL}$ and their ability to detect(diagnose) cancer in an orthotopic graft model mouse of HER2-negative breast cancer.

\section{Materials and Methods}

Preparation of HL. Hybrid liposomes (HL) were prepared by sonication of a mixture containing $90 \mathrm{~mol} \% \mathrm{~L}$ - $\alpha$-dimyristoylphosphatidylcholine (DMPC, NOF Co, Ltd., Tokyo, Japan) and $10 \mathrm{~mol} \%$ polyoxyethylene [25] dodecyl ether $\left(\mathrm{C}_{12}(\mathrm{EO})_{25}\right.$, Nikko Chemicals Co., Ltd., Tokyo, Japan, ) in $5 \%$ glucose solution using a bath type sonicator (ULTRASONIC-CLEANER- WT-200-M, Tokyo, Japan) at $45^{\circ} \mathrm{C}$ with $200 \mathrm{~W}$, and filtered with $0.20 \mu \mathrm{m}$ cellulose acetate filter (Advantec, Tokyo, Japan).

Dynamic light scattering measurements. The diameter of HL was measured with a light scattering spectrometer (ELSZ-0, Otsuka Electronics, Osaka, Japan) using a He-Ne laser $(633 \mathrm{~nm})$ at a $90^{\circ}$ scattering angle. The hydrodynamic diameter $\left(d_{\text {hy }}\right)$ was calculated using the Stokes-Einstein formula (Equation 1), where $\mathrm{K}$ is the Boltzmann constant, $\mathrm{T}$ is the absolute temperature, $\eta$ is the viscosity and $\mathrm{D}$ is the diffusion coefficient:

$d_{\mathrm{hy}}=\kappa T / 3 \pi \eta D$

(Equation 1)

Cell culture. Human breast cancer (MDA-MB-453) cell lines were obtained from Riken Cell Bank (Tsukuba, Japan). Cells were cultured in L-15 medium (GIBCO, Gaithersburg, MD, USA) supplement with penicillin (100 units $/ \mathrm{ml})$, streptomycin $(50 \mathrm{~g} / \mathrm{ml})$ and $10 \%$ fetal bovine serum (FBS, HyClone Laboratories Inc., UT, USA) in a humidified atmosphere at $37^{\circ} \mathrm{C}$. Normal mouse breast cells were obtained from normal healthy mice according to a previous method (24-25), and cultured using RPMI 1640 medium supplemented with penicillin $100 \mathrm{U} / \mathrm{ml}$, streptomycin $50 \mu \mathrm{g} / \mathrm{ml}$ and $10 \%$ FBS.

Assessment of $50 \%$ inhibitory concentration $\left(I_{50}\right)$ of $H L$ in vitro. The fifty-percent inhibitory concentration $\left(\mathrm{IC}_{50}\right)$ of $\mathrm{HL}$ on the growth of MDA-MB-453 cells was determined on the basis of WST-8 [2(2-methoxy-4-nitrophenyl)-3-(4-nitrophenyl)-5-(2,4-disulfophenyl)$2 \mathrm{H}$ tetrazolium, monosodium salt] assay (Cell Counting Kit-8, Dojindo Laboratories, Kumamoto, Japan). MDA-MB-453 cells $\left(1.5 \times 10^{5}\right.$ cells $\left./ \mathrm{ml}\right)$ were seeded in 96 -well plates and cultured in a $5 \% \mathrm{CO}_{2}$ humidified incubator at $37^{\circ} \mathrm{C}$ for $24 \mathrm{~h}$. Cells were cultured for a further $48 \mathrm{~h}$ after adding DMPC (0.25-2.0 mM), and HL (0.25$2.0 \mathrm{mM}$ on the basis of DMPC concentration). WST- 8 solution was added and the cells were incubated for $3 \mathrm{~h}$. The absorbance at a wavelength of $450 \mathrm{~nm}$ was measured by a microplate reader (Thermo, CA, USA). The inhibitory effects of HL on the growth of MDA-MB-453 cells were evaluated by $A_{\text {mean }} / A_{\text {control}}$, where $A_{\text {mean }}$ and $A_{\text {control }}$ denote the absorbance of water-soluble formazan, in the presence and absence of HL, respectively.

Apoptotic DNA measurements using flow cytometer. MDA-MB-453 cells were seeded at a density of $1.5 \times 10^{5}$ cells $/ \mathrm{ml}$ in $60 \mathrm{~mm}$ dish and incubated in a humidified atmosphere of $5 \% \mathrm{CO}_{2}$ at $37^{\circ} \mathrm{C}$ for $24 \mathrm{~h}$. DMPC (0.1-0.6 mM), and HL (0.1-0.6 mM on the basis of DMPC concentration) were added into each dish and the dishes were incubated for $48 \mathrm{~h}$. Cells were centrifuged and then suspended in PBS(-) containing $1 \mathrm{mg} / \mathrm{ml}$ RNase, $0.1 \%$ Triton X-100 and $40 \mu \mathrm{g} / \mathrm{ml}$ propidium iodide (PI, Molecular Probes, OR, USA) in a dark room. The percentage of apoptotic cells was analyzed using a flow cytometer (Cyto FLEX, Beckman Coulter, CA, USA).

Fluorescence depolarization method. Membrane fluidity of intact MDA-MB-453 cells was evaluated on the basis of fluorescence depolarization method with the fluorescent probe 1,6-diphenyl-1,3,5hexatriene (DPH) (Nacalai Tesque, Japan) (18, 26-27). After the preincubation for $24 \mathrm{~h}$, the cells were treated with $0.05 \%$ Trypsin/EDTA and suspended in phosphate buffered-saline (PBS (-)), and then DPH $(0.1 \mu \mathrm{M})$ was added into the cell suspension $\left(1.0 \times 10^{6}\right.$ cells $\left./ \mathrm{ml}\right)$. The changes of cell membrane fluidity for DPH-labeled MDA-MB-453 cells $\left(2.5 \times 10^{5}\right.$ cells $\left./ \mathrm{ml}\right)$ after treatment with HL were evaluated. After labeling of MDA-MB-453 cells with DPH, plasma membrane fluidity ( $p$-value) was measured using a fluorescence spectrophotometer (F-7100, HITACHI, Co. Ltd., Tokyo, Japan).

Assessment of therapeutic effects of $H L$ in vivo. The mice were handled in accordance with the guidelines for animal experimentation set out in Japanese law. The animal studies were approved by the Committee on Animal Research of Sojo University. BALB/c-R/J mice were kindly provided by Prof. Okada (Kumamoto University, Japan) (28) and bred in an environment that was $100 \%$ freshly ventilated every $1 \mathrm{~h}$ for 14 times and had room temperature $25 \pm 1^{\circ} \mathrm{C}$, humidity $50 \pm 10 \%$ and $12 \mathrm{~h}$ illumination cycle. The MDAMB- 453 cells $\left(5.0 \times 10^{6}\right.$ cells in $50 \mu \mathrm{l}$ of matrigel) were orthotopically implanted into the mammary gland of anesthetized mice. The mice were randomly grouped on the basis of tumor volume by the stratified randomization method at 14 days after inoculation of MDA-MB-453 cells. Five mice were included in each group. HL (Dose: $136 \mathrm{mg} / \mathrm{kg}$ for DMPC) were intravenously administered once a day for 21 days following the inoculation of MDA-MB-453 cells. The tumor volume was measured using vernier caliper and calculated 
using the equation of $V=0.5 \times a^{2} \times b$, where $\mathrm{a}$ and $\mathrm{b}$ denote the smallest and longest superficial diameter, respectively $(20,29-30)$. Tumors on mammary gland were removed from anaesthetized mice after completion of administration with HL and weighed.

Terminal deoxynucleotidyl tranferase-mediated dUTP-biotin nick end labeling (TUNEL) method in vivo. Detection of apoptotic cells was performed using the TUNEL method included in the apoptosis detection kit (S7100, Merck Millipore, Darmstadt, Germany) according to manufacturer's directions. The tumors on mammary gland were removed from anesthetized orthotopic graft model mice of breast cancer after the treatment with HL and fixed in $10 \%$ formalin solution. Paraffin-embedded sections were made, and detection of apoptotic cells was performed on the basis of the TUNEL assay. The mammary gland sections including tumor were stained with $3,3^{\prime}$-DAB chromogen and observed by an optical microscope.

Fusion and accumulation of HL into the cell membrane. The fusion and accumulation of HL carrying a fluorescence probe (Indocyanine Green; ICG, Tokyo Chemical Industry Co., Ltd., Tokyo, Japan) into the membrane of MDA-MB-453 cells was observed using fluorescence cell imaging system (EVOS FL; Thermo Fisher Scientific Inc., MA, USA). MDA-MB-453 $\left(2.0 \times 10^{5}\right.$ cells $\left./ \mathrm{ml}\right)$ cells and normal breast cells $\left(1.0 \times 10^{5}\right.$ cells $\left./ \mathrm{ml}\right)$ were seeded in glass bottom dishes and incubated in a $5 \% \mathrm{CO}_{2}$ humidified incubator at $37^{\circ} \mathrm{C}$ for $24 \mathrm{~h}$. The cells were treated with HL carrying a fluorescence probe $\left([\mathrm{DMPC}]=100 \mu \mathrm{M},\left[\mathrm{C}_{12}(\mathrm{EO})_{25}\right]=11.3 \mu \mathrm{M}\right.$, $[\mathrm{ICG}]=1.1 \mu \mathrm{M}$ ) for $150 \mathrm{~min}$. The nuclei of cells were stained with Hoechst 33342 (Molecular Probes, Inc., OR, USA) solution for 30 min. The stained cells were observed using fluorescence cell imaging system (710/40 nm Excitation; 775/46 nm Emission).

Accumulation of HL into tumor of orthotopic graft mouse model of breast cancer. The accumulation of HL carrying ICG (HL/ICG) into tumor on the mammary gland in orthotopic graft model mice of breast cancer was observed noninvasively using fluorescence macroscopic in vivo imaging system (Excitation: 725-825 nm, Emission: 790-900 nm, AEQUORIA, Hamamatsu Photonics K.K., Hamamatsu, Shizuoka, Japan). HL/ICG (Dose: $136 \mathrm{mg} / \mathrm{kg}$ for DMPC) was intravenously administered in mice at 28 days after the MDA-MB-453 cells $\left(5.0 \times 10^{6}\right.$ cells in $50 \mu \mathrm{l}$ of matrigel $)$ were inoculated into mammary gland. After the injection of HL/ICG, the biodistribution of the HL/ICG was investigated at $0.5,2,24,48 \mathrm{~h}$ using fluorescence macroscopic in vivo imaging system. The tumors on mammary gland tissues were removed from anesthetized orthotopic graft model mice of breast cancer $24 \mathrm{~h}$ after the treatment with HL and observed by a fluorescence microscope.

Statistical analysis. Results are presented as mean \pm S.D. Data were statistically analyzed using the Student's $t$-test. A $p$-Value of less than 0.05 was considered to represent a statistically significant difference.

\section{Results}

Physical properties of $H L$. The morphology of HL composed of $90 \mathrm{~mol} \%$ DMPC and $10 \mathrm{~mol}_{\%} \mathrm{C}_{12}(\mathrm{EO})_{25}$ was examined on the basis of dynamic light scattering measurements. Hydrodynamic diameter $\left(d_{\text {hy }}\right)$ of HL was under $100 \mathrm{~nm}$ with the distribution being narrow and single. HL were stable for more than one month. In contrast, DMPC liposomes were unstable and precipitated after 14 days.

Inhibitory effects of $H L$ on the growth of human breast cancer cells. The inhibitory effects of HL on the growth of human breast cancer (MDA-MB-453) cells were evaluated using the WST-8 assay. The results are shown in Figure 1. Fifty percent inhibitory concentration $\left(\mathrm{IC}_{50}\right)$ value of DMPC liposomes on the growth of MDA-MB- 453 cells was $413 \mu \mathrm{M}$. In contrast, $\mathrm{IC}_{50}$ value of MDA-MB-453 cells treated with $\mathrm{HL}$ was $169 \mu \mathrm{M}$, about one-third of that of DMPC liposomes. HL remarkably inhibited the growth of MDA-MB-453 cells.

DNA fragmentation by HL in human breast cancer cells. Apoptotic DNA in MDA-MB-453 cells treated with HL was examined using flow cytometer. The results are shown in Figure 2. HL treatment resulted in a dose dependent increased in apoptotic DNA rate in MDA-MB-453 cells which reached $72 \%$. On the other hand, the apoptotic DNA rate in MDAMB-453 cells treated with DMPC liposomes was $4 \%$.

Change of membrane fluidity of human breast cancer cells by $H L$. Membrane fluidity of MDA-MB-453 cells after the treatment with HL was investigated using the fluorescent lipid probe, DPH. The results are shown in Figure 3. Fluorescence depolarization ( $p$-value), indicating plasma membrane fluidity of MDA-MB-453 cells treated with HL, was significantly decreased as compared with that of control and DMPC liposomes. Membrane fluidity of DMPC liposomes was smaller than that of HL (18).

Therapeutic effects of HL in an orthotopic graft model mice of breast cancer. The time course of tumor volume changes in an orthotopic graft model of breast cancer after the treatment with HL was measured. HL were intravenously administered once a day for 21 days after the inoculation of MDA-MB-453 cells into mammary grand. The results are shown in Figure 4. The average tumor volumes were $144.64 \pm 29.79 \mathrm{~mm}^{3}$, $122.21 \pm 22.44(p<0.05 v s$. control) and 92.49 $\pm 14.04(p<0.05$ vs. control) $\mathrm{mm}^{3}$ in the control, DMPC and HL group, respectively. A notable reduction of tumor volume (64\%) was obtained in orthotopic graft model mice of breast cancer that was intravenously treated with HL without drugs after the inoculation of MDA-MB-453 cells. Next the relative tumor weight in the orthotopic graft model mice of breast cancer treated with HL was examined. The results are shown in Figure 5. Orthotopic graft model mice of breast cancer treated with HL $(0.389 \pm 0.044 \mathrm{~g} / 100 \mathrm{~g}$ b.w., $p<0.05 v s$. control) had a significantly lower relative tumor weight compared with the animals in control $(0.514 \pm 0.117 \mathrm{~g} / 100 \mathrm{~g}$ b.w. $)$ and DMPC group $(0.493 \pm 0.092 \mathrm{~g} / 100 \mathrm{~g}$ b.w.). Next, the therapeutic effects of HL on orthotopic graft model mice of breast cancer were observed by performing autopsy. As shown in Figure 6, 


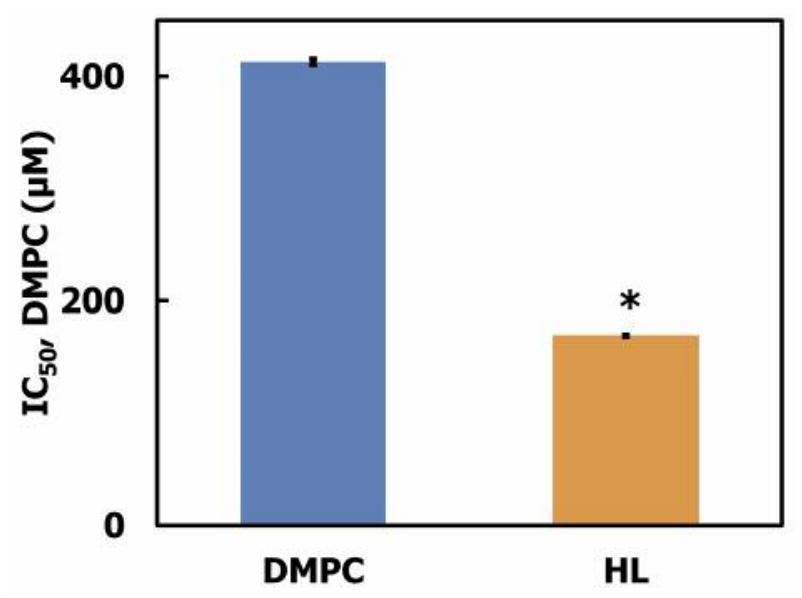

Figure 1. 50\% inhibitory concentration $\left(I C_{50}\right)$ of $H L$ and DMPC liposomes on the growth of MDA-MB-453 cells for $48 \mathrm{~h}$. Values are presented as mean \pm S.E. ${ }^{*} p<0.05$ (vs. DMPC).

reduction of tumor in orthotopic graft model mice of breast cancer treated with HL was observed, while enlargement of tumor in the control group was confirmed.

Induction of apoptosis by HL for orthotopic graft model mice of breast cancer. The mechanism of the therapeutic effects of HL on tumors of the mammary gland of orthotopic graft model mice of breast cancer was examined using the TUNEL method in vivo. HL were intravenously administered in the orthotopic graft model mice of breast cancer once a day for 21 days after the inoculation of MDA-MB-453 cells. Tumors on mammary gland were removed from anaesthetized mice immediately after the treatment with HL. Induction of apoptosis by HL was evaluated using TUNEL staining. The results are shown in Figure 7. Many apoptotic cells were observed in tissue sections of tumor on the mammary gland of orthotopic graft model mice of breast cancer after intravenous administration with HL. On the other hand, few apoptotic cells were observed following administration of DMPC.

Selective accumulation of HL in MDA-MB-453 cells in vitro. Accumulation of HL (HL/ICG) carrying ICG for MDA-MB-453 cells was examined using fluorescence microscope. The results are shown in Figure 8A. Remarkable accumulation of HL/ICG into MDA-MB-453 cells was attained, while less accumulation of DMPC/ICG and $\mathrm{C}_{12}(\mathrm{EO})_{25} / \mathrm{ICG}$ was observed. ICG alone did not accumulate in MDA-MB-453 cells. Next, accumulation of HL/ICG in normal breast cells was examined. The results are shown in Figure 8B. HL/ICG did not accumulate in normal breast cells. Selective accumulation of HL/ICG only in MDA-MB-453 cells but not in normal breast cells was obtained in vitro.
Accumulation of HL into tumors in vivo after a prolonged period of time. Accumulation of HL/ICG into tumors of orthotopic graft model mice of breast cancer was assessed in vivo using fluorescence imaging. MDA-MB-453 cells were orthotopically transplanted into mammary gland of BALB/c-R/J mice. HL/ICG intravenously administered once at 28 days after the MDA-MB-453 cells were inoculated to mammary gland of mice. Accumulation of HL/ICG into tumor was noninvasively investigated using fluorescence macroscopic in vivo imaging $24 \mathrm{~h}$ after the intravenous injection of HL/ICG. Furthermore, strong green fluorescence indicating accumulation of HL/ICG into the tumor on mammary gland resected from anesthetized model mice was observed at $24 \mathrm{~h}$ (Figure 9). In contrast, less accumulation of ICG in the tumors of the orthotopic graft model mice of breast cancer was observed within $24 \mathrm{~h}$ after the injection of DMPC/ICG, $\mathrm{C}_{12}(\mathrm{EO})_{25} / \mathrm{ICG}$. Disappearance of green fluorescence of ICG from the orthotopic graft model mice of breast cancer within $24 \mathrm{~h}$ following injection of ICG alone were revealed. HL could accumulate into tumor cells on mammary grand of orthotopic graft model mice of breast cancer for a prolonged period of time.

\section{Discussion}

Molecular targeted therapy for tumors has been used for breast cancer. HER-2 is overexpressed in $30 \%$ of patients with breast cancer (4), and therefore anti-HER-2 antibody (Trastuzumab) targeting HER-2 has been developed (5-7). However, the efficacy of Trastuzumab for patients with HER2negative breast cancer and trastuzumab-resistant Her2-positive breast cancer is limited $(7,8)$. Therefore, anti-cancer drugs against HER2-negative breast cancer are needed.

Theranostics is a treatment strategy that combines therapeutics with diagnostics. Theranostic medicines have the ability for selective accumulation in cancer tissue. Theranostic medicines can selectively deliver effective therapeutic action. Theranostic medicines should be safe and nontoxic products. ICG has the attractive properties of very low toxicity and high absorptance in a wavelength range of 600 to $900 \mathrm{~nm}$ (11), which is a transparent wavelength for biological tissues $(8-10,12)$. A carrier containing ICG as a fluorescent probe and having high selectivity for cancer will provide the possibility of detecting cancer.

The fluidity of membranes of tumor cells is generally higher compared with normal ones. Remarkable long-term accumulation of HL carrying ICG into the tumor in xenograft model mice of colon cancer has also been reported $(23,31)$. Furthermore, therapeutic effects of HL without any drugs in the xenograft model mice of colon cancer have been revealed $(23,31)$. Accumulation of $\mathrm{HL}$ into human colon cancer (HCT116) cells without affecting the normal mouse colon cells using fluorescence microscopy have been reported (31). These results suggest 


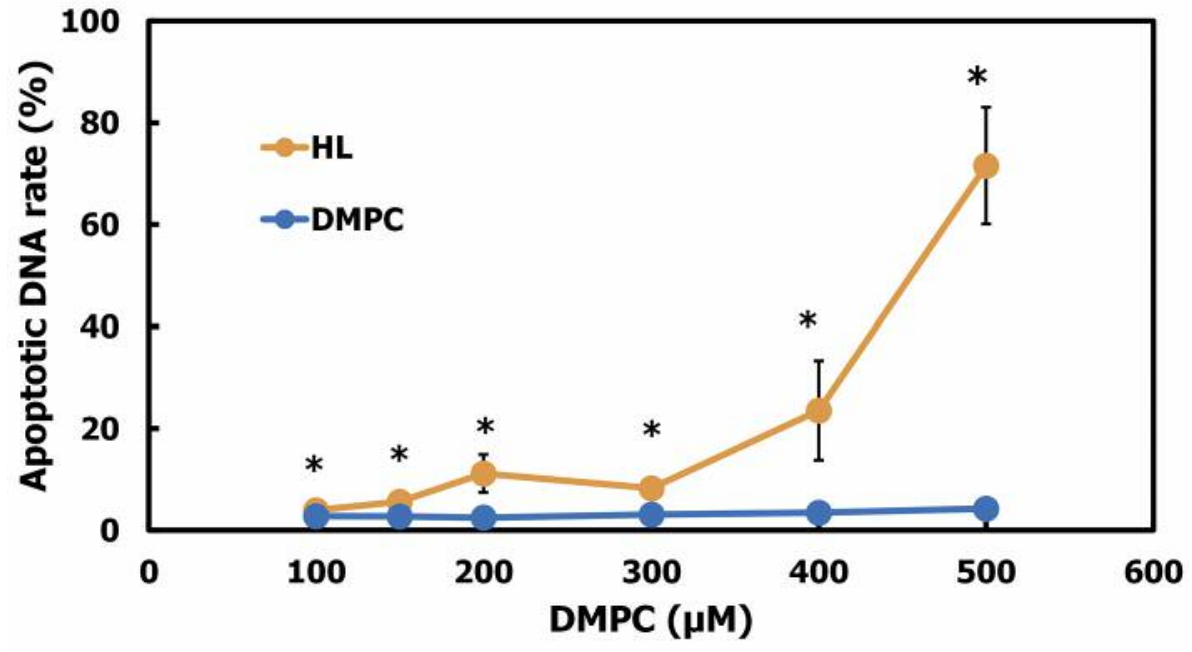

Figure 2. Apoptotic DNA rate for MDA-MB-453 cells treated with HL for 48 h. Values are presented as mean $\pm S . E . * p<0.05$ (vs. DMPC).

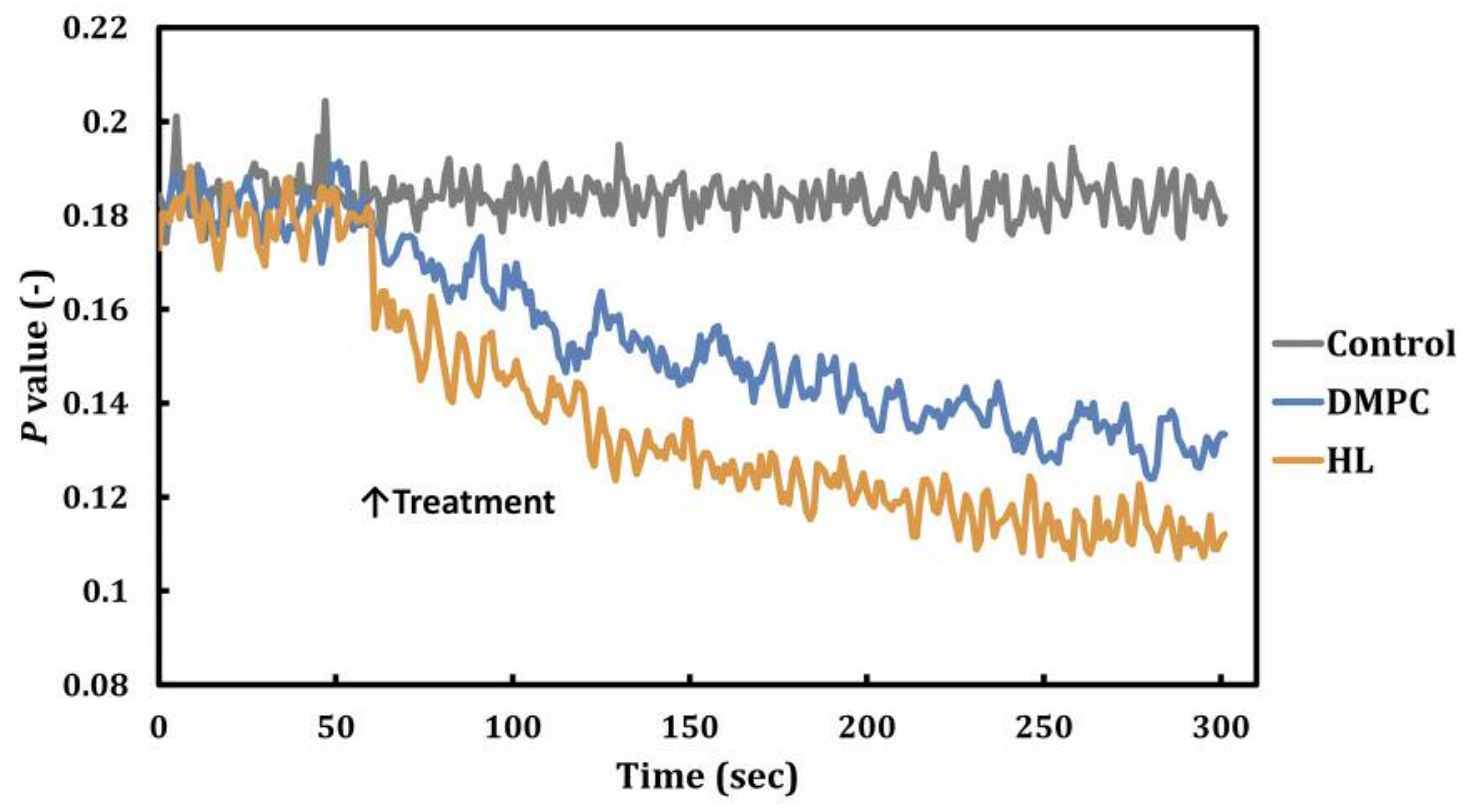

Figure 3. Time courses of fluorescence polarization (p-value) change for DPH-labeled MDA-MB-453 cells after the treatment with HL.

that HL can distinguish between normal and tumor cells on the basis of the fluidity of cell membrane.

According to the morphology of HL, $d_{\text {hy }}$ of HL has been kept stable for more than one month at room temperature. HL can be stored for a longer time span before its application in vivo. There is a possibility that HL below $100 \mathrm{~nm}$ in diameter might evade the reticular endothelial system (RES) (32) and also be the appropriate candidate for in vivo and clinical intravenous administration.
Theranostics (detection and therapy of cancer) properties of HL were examined using orthotopic graft model mouse of breast cancer of HER2-negative.

The $\mathrm{IC}_{50}$ values of $\mathrm{HL}$ on the inhibition of the growth of MDA-MB-453 cells were remarkably lower than that of DMPC liposomes. HL treatment also resulted in a dose dependent increase in the apoptotic DNA rate in MDA-MB-453. These results indicate that $\mathrm{HL}$ induced apoptosis and inhibited growth of MDA-MB-453 cells. Membrane fluidity of MDA-MB-453 


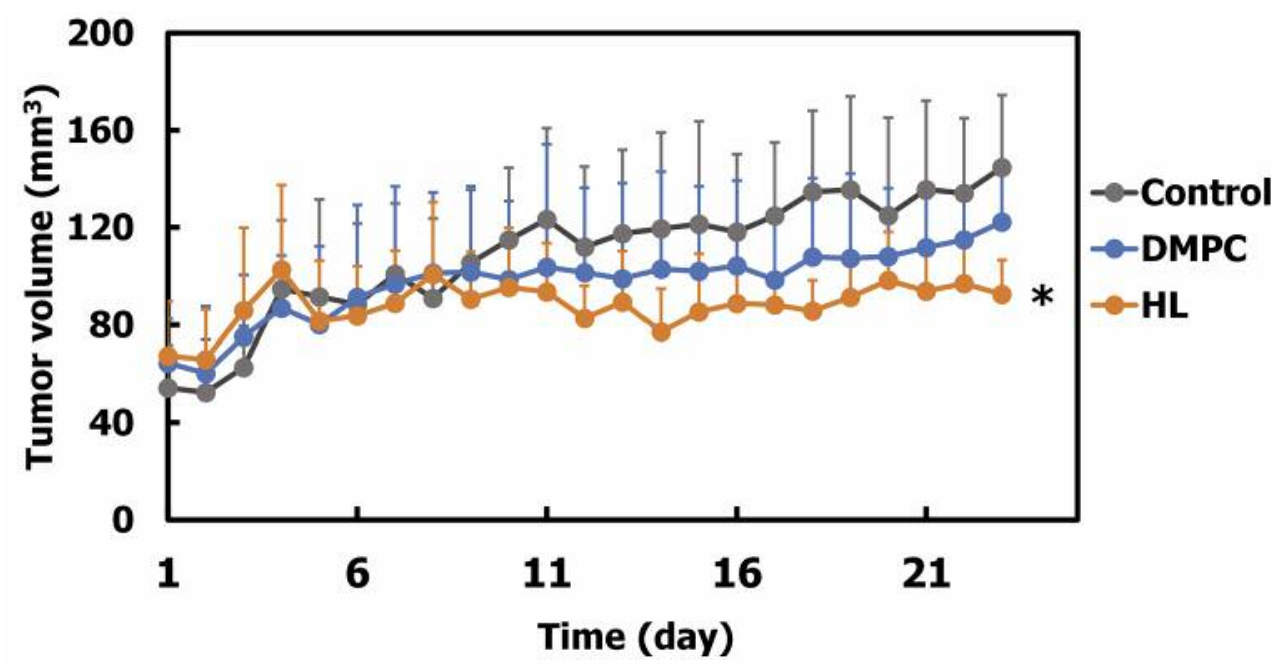

Figure 4. Tumor volume change of orthotopic graft model mice of breast cancer treated with HL after inoculation of MDA-MB-453 cells to the mammary gland. Values are presented as mean \pm S.D. ${ }^{*} p<0.05$ (vs. control, DMPC).

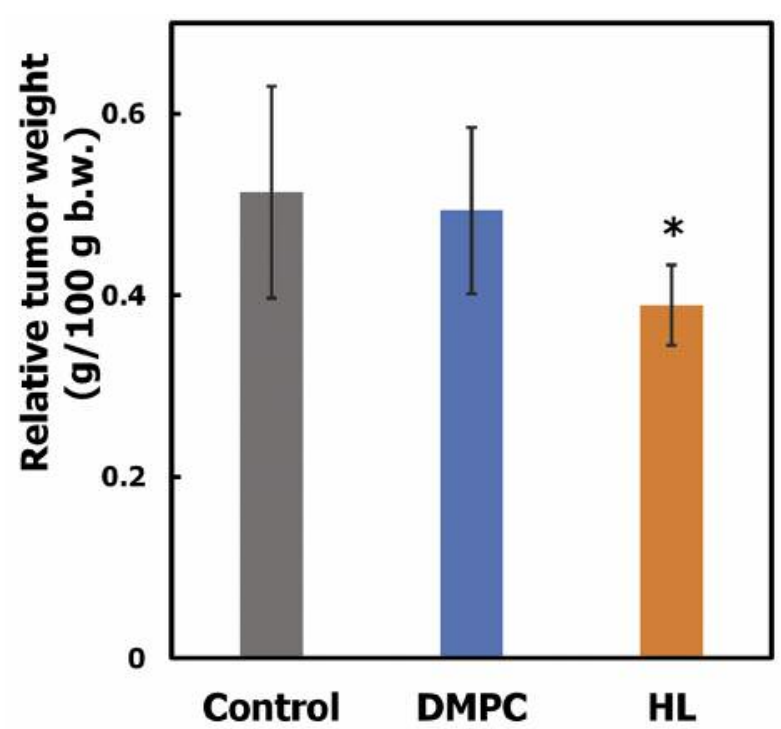

Figure 5. Relative tumor weight of orthotopic graft model mice of breast cancer treated with HL after inoculation of MDA-MB-453 cells to the mammary gland. Values are presented as mean \pm S.D. ${ }^{*} p<0.05$ (vs. control, DMPC).

cells treated with HL was significantly increased as compared with that of control and DMPC liposomes. These results suggest that the increase in the membrane fluidity could be related to early events in HL- induced apoptosis.

The therapeutic effects of HL for orthotopic graft model mice of breast cancer after the inoculation to mammary gland were examined. Reduction of tumor volume and

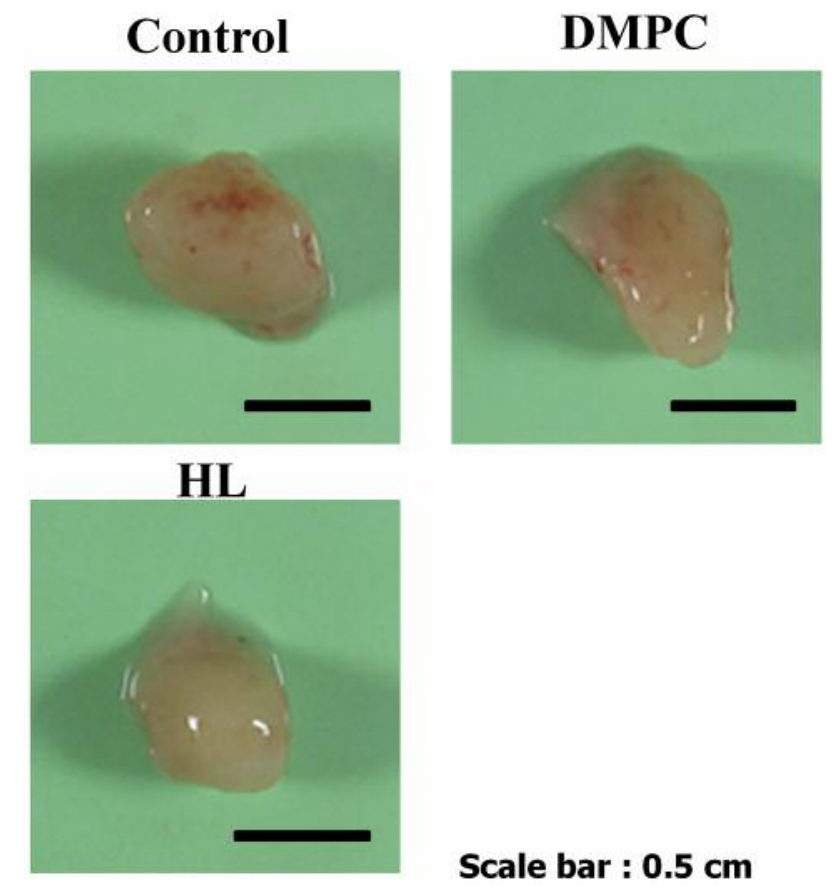

Figure 6. Micrographs of tumor in mammary gland on orthotopic graft model mice of breast cancer after the treatment with $H L$ using $H E$ staining. Scale bar: $1 \mathrm{~mm}$.

weight in the group of mice treated with HL was observed, while enlargement of tumors in control and DMPC groups was confirmed. These results indicate that HL could be effective in an orthotopic graft model mice of breast cancer 
Control
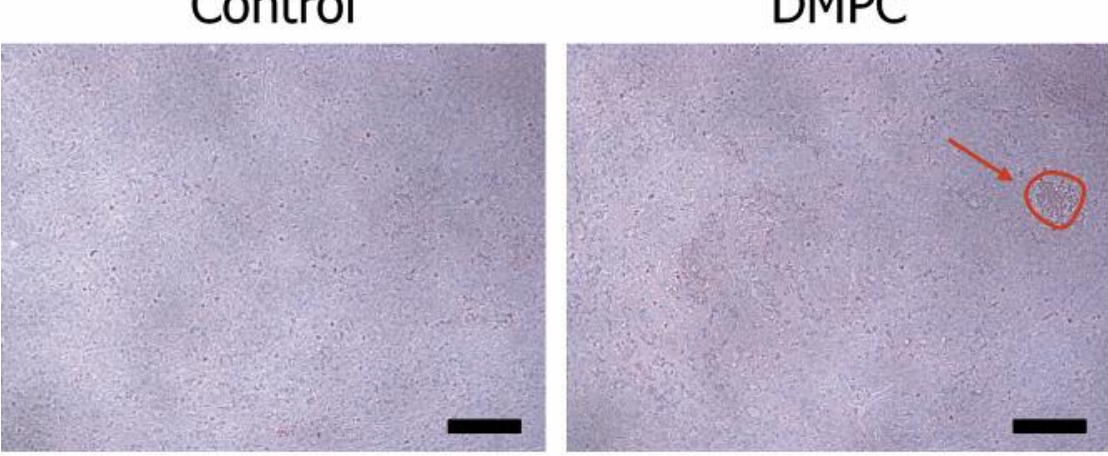

$\mathrm{HL}$

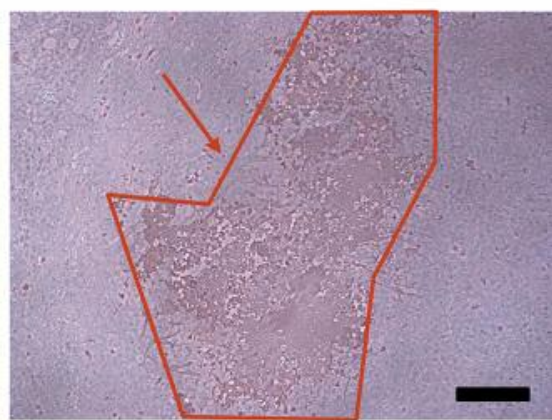

Scale bar : $100 \mu \mathrm{m}$ Arrow : Apoptotic cells

Figure 7. Micrographs of tissue sections of tumor on mammary gland of orthotopic graft model mice of breast cancer after the treatment with HL using the TUNEL method. Arrows: apoptotic cells. Scale bar: $100 \mu \mathrm{m}$.

A

MDA-MB-453 cells
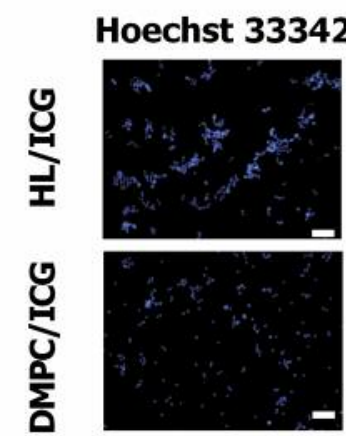

总

\&
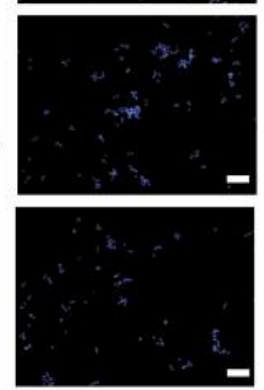

ICG
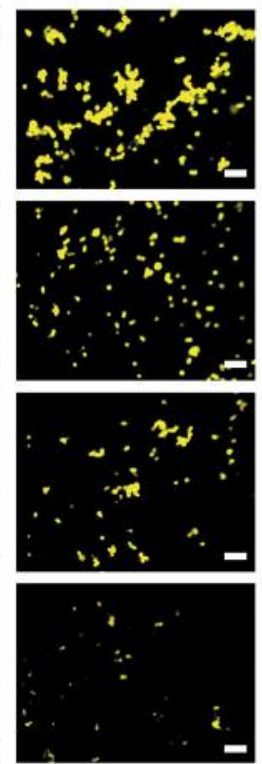

\section{Overlay}
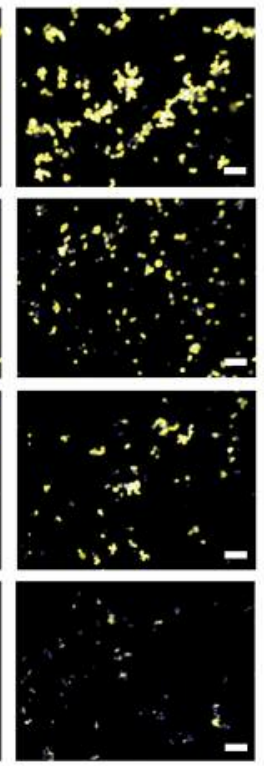

B

\section{Normal breast cells}
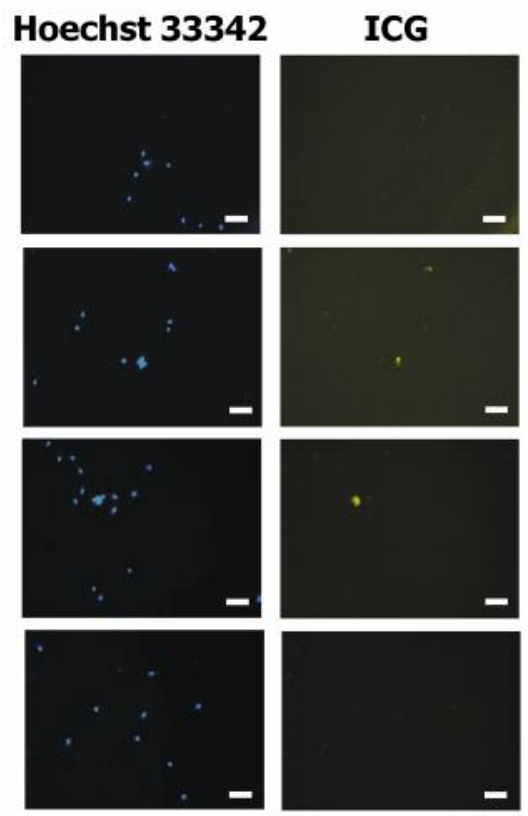
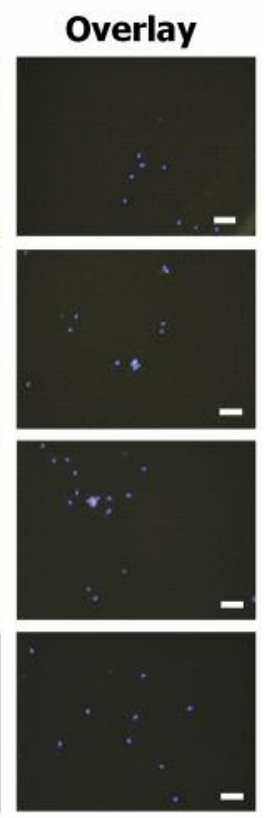

Scale bar : $100 \mu \mathrm{m}$

Figure 8. Enhanced selective accumulation of HL (HL/ICG) carrying ICG for MDA-MB-453 cells using fluorescence microscope. A) Fluorescence micrographs of MDA-MB-453 cells after the treatment with HL/ICG for $3 \mathrm{~h}$. Scale bar: $100 \mu \mathrm{m}$. B) Fluorescence micrographs of normal breast cells after the treatment with HL/ICG for $3 \mathrm{~h}$. Scale bar: $100 \mu \mathrm{m}$.

in vivo. Many apoptotic cells were observed in the tumor section of breast cancer orthotopic graft model mice treated with HL using the TUNEL method. These results indicate that intravenous injection of HL inhibits the growth of
MDA-MB-453 cells by inducing apoptosis in breast cancer orthotopic graft model mice .

With regard to detection (diagnosis) of breast cancer by HL, remarkable enhanced and selective accumulation of HL 


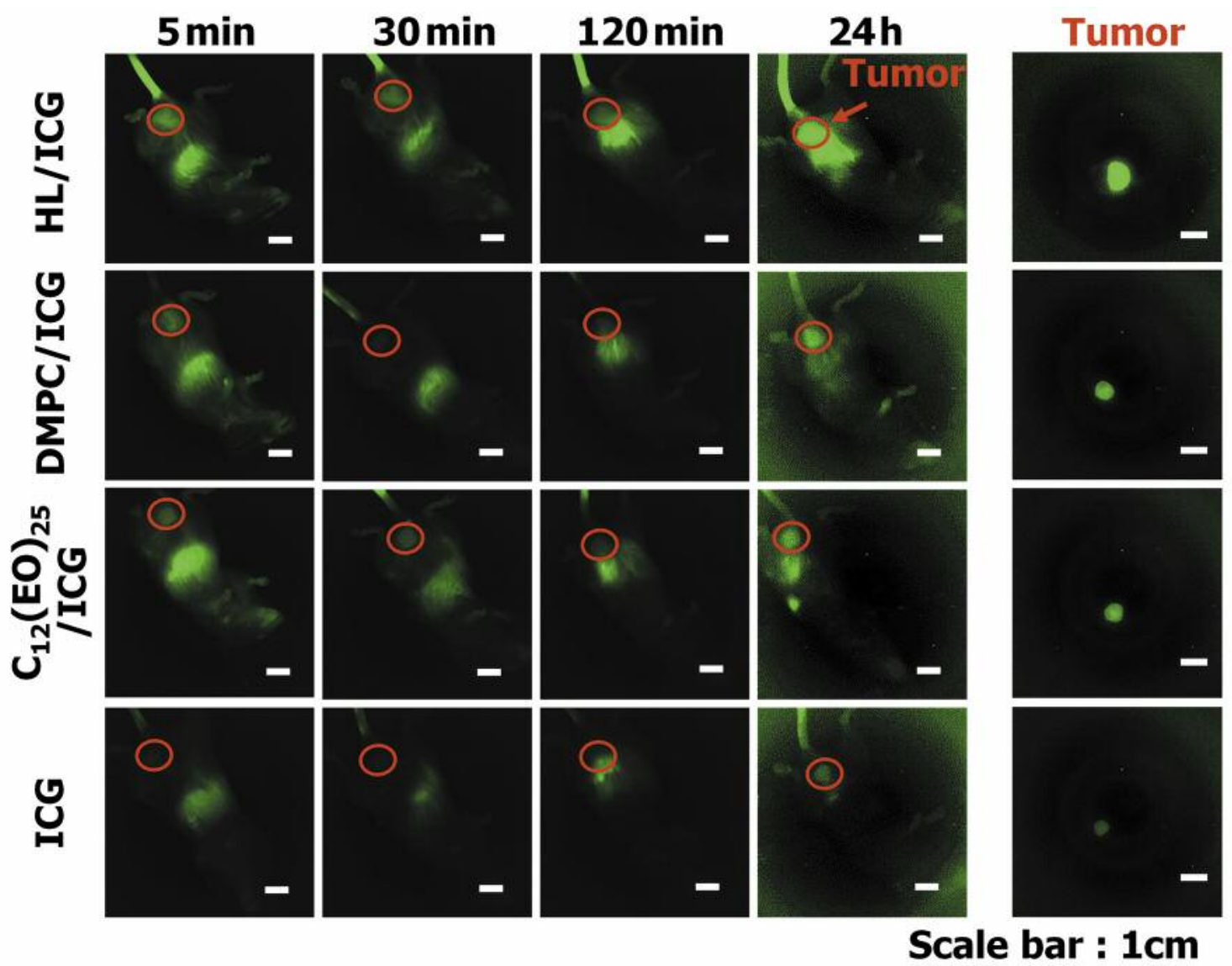

Figure 9. Enhanced long-term accumulation of HL (HL/ICG) carrying ICG intravenously administered once at 28 days after the inoculation of MDA-MB-453 cells on mammary gland of the orthotopic graft model mouse of breast cancer. Circles indicate tumors.

(HL/ICG) carrying ICG in MDA-MB-453 cells was observed using the fluorescence microscope. In contrast HL/ICG did not accumulate in normal breast cells. The membrane fluidity of tumor cells is higher as compared with that of normal cells (33-35). These results suggest that there is enhanced selective in vitro accumulation (diagnosis) of HL/ICG only in breast cancer cells having high membrane fluidity, but not in normal breast cells. Enhanced accumulation of HL/ICG into the tumor of orthotopic graft model mice of breast cancer was noninvasively also observed $24 \mathrm{~h}$ after the intravenous injection of $\mathrm{HL} /$. In contrast, less accumulation for ICG in the orthotopic graft model mice of breast cancer was observed within $24 \mathrm{~h}$ after the injection of DMPC/ICG, $\mathrm{C}_{12}(\mathrm{EO})_{25} / \mathrm{ICG}$. Disappearance of green fluorescence of ICG from orthotopic graft model mice of breast cancer within $24 \mathrm{~h}$ following injection of ICG alone were revealed. ICG has been used to evaluate liver function in clinical practice, because ICG is immediately removed from circulation through liver $(9-10,12)$. So, DMPC/ICG, $\mathrm{C}_{12}(\mathrm{EO})_{25} / \mathrm{ICG}$, and ICG alone could be excreted from liver through the intestines. These results indicate that HL could accumulate into tumor cells in mammary gland of orthotopic graft model mice of breast cancer for a prolonged period of time. It is noteworthy that detection (diagnosis) of tumor of orthotopic graft model mice of breast cancer by accumulation HL/ICG is highly selective.

No side-effects of HL in chronic toxicity tests in healthy rats have been reported in vivo (22). We have already reported the pharmacokinetics of HL using normal mice and rats $(20,22)$. HL circulated in blood for 3 hours after intravenous administration to normal mice, and then metabolized in the liver (20).

In clinical application, a prolonged survival of more than one year was attained in one patient with lymphoma in last stage after the intravenous injection of HL without any sideeffects. In addition, a remarkable reduction of the lymph node neoplasm (solid tumor) was observed after local administration (2 times/week) of HL (22). These results suggest that HL could be a novel theranostic agent for breast cancer without severe side-effects. 


\section{Conclusion}

It is established, for the first time, that hybrid liposomes (HL) have therapeutic effects and for the ability to detect tumors in an orthotopic graft model mouse of breast cancer. HL having hydrodynamic diameter under $100 \mathrm{~nm}$ were successfully preserved over 4 weeks.

Regarding the therapeutic effects of HL for breast cancer, HL without drugs inhibited the growth of MDA-MB-453 cells and induced apoptosis in vitro. Remarkable reduction of relative tumor weight on mammary gland of orthotopic graft model mice of breast cancer intravenously administered with HL was also obtained. Induction of apoptosis for MDA-MB453 cells in tumors of orthotopic graft model mice of breast cancer intravenously administered with HL was observed using the TUNEL method.

Regarding the ability of HL to detect (diagnose) breast cancer, enhanced selective accumulation of HL/ICG carrying a fluorescence probe (ICG) only in breast cancer cells having high membrane fluidity, but not in normal breast cells was confirmed in vitro.

Enhanced accumulation of HL/ICG into the tumor cells in mammary gland of orthotopic graft model mice of breast cancer was non-invasively observed after the intravenous administration with HL/ICG in vivo. The results of this study indicate that HL could be of theranostic significance in patients with breast cancer in the future.

\section{Conflicts of Interest}

No potential conflict of interest was reported by the Authors.

\section{Acknowledgements}

This work was supported in part by a Grant-in-Aid for Science Research from the Ministry of Education, Science, and Culture of Japan (Nos. 17K01383 and 17K05944).

\section{References}

1 Rostas JW and DL: Current operative management of breast cancer: an age of smaller resections and bigger cures. Int $\mathrm{J}$ Breast Cancer 2012: 516417, 2012.

2 Green MC, Buzdar AU, Smith T, Ibrahim NK, Valero V, Rosales MF, Cristofanilli M, Booser DJ, Rivera LPE, Theriault RL, Carter C, Frye D, Hunt KK, Symmans WF, Strom EA, Sahin AA, Sikov W and Hortobagyi BN: Weekly Paclitaxel improves pathologic complete remission in operable breast cancer when compared with Paclitaxel once every 3 weeks. J Clin Oncol 23: 5983-5992, 2005.

3 Makhoul I and Kiwan E: Neoadjuvant systemic treatment of breast cancer. J Surg Oncol 103: 348-357, 2011.

4 Slamon DJ, Clark GM, Wong SG, Levin WJ, Ullrich A and McGuire WL: Human breast cancer: correlation of relapse and survival with amplification of the HER-2/neu oncogene. Science 235: 177-182, 1987.
5 Weiner LM, Dhodapkar MV and Ferrone S: Monoclonal antibodies for cancer immunotherapy. Lancet 373: 1033-1040, 2009.

6 Slamon DJ, Leyland-Jones B, Shak S, Fuchs H, Paton V, Bajamonde A, Fleming T, Eiermann W, Wolter J, Pegram M, Baselga $\mathrm{J}$ and Norton L: Use of chemotherapy plus a monoclonal antibody against HER2 for metastatic breast cancer that overexpresses HER2. N Eng1 J Med 344: 783-792, 2011.

7 Morrow PK, Wulf GM, Ensor J, Booser DJ, Moore JA, Flores PR, Xiong Y, Zhang S, Krop IE, Winer EP and Kindelberger DW: Phase I/II study of trastuzumab in combination with everolimus (RAD001) in patients with HER2-overexpressing metastatic breast cancer who progressed on trastuzumab-based therapy. J Clin Oncol 29: 3126-3132, 2011.

8 Maarek JM, Holschneider DP, Harimoto J, Yang J, Scremin OU and Rubinstein EH: Measurement of cardiac output with indocyanine green transcutaneous fluorescence dilution technique. Anesthesiology 100: 1476-1483, 2004.

9 Hoekstra LT, de Graaf W, Nibourg GA, Heger M, Bennink RJ, Stieger B and van Gulik TM: Physiological and biochemical basis of clinical liver function tests: a review. Ann Surg 257: $27-$ 36, 2013.

10 Vos JJ, Wietasch JK, Absalom AR, Hendriks HG and Scheeren TW: Green light for liver function monitoring using indocyanine green? An overview of current clinical applications. Anaesthesia 69: 1364-1376, 2014.

11 Baohong Y, NanGuang C and Quing Z: Emission and absorption properties of indocyanine green in Intralipid solution. Biomed Opt 9: 497-503, 2004.

12 De Gasperi A, Mazza E and Prosperi M: Indocyanine green kinetics to assess liver function: Ready for a clinical dynamic assessment in major liver surgery? World J Hepatol 8: 355-367, 2016.

13 Ueoka R, Moss RA, Swarup S, Matsumoto Y, Strauss G and Murakami Y: Extraordinary micellar enantioselectivity coupled to altered aggregate sturucture. J Am Chem Soc 107: 2185-2186, 1985.

14 Ueoka R, Matsumoto Y, Moss RA, Swarup S, Sugii A, Harada J, Kikuchi Y and Murakami Y: Membrane matrix for the hydrolysis of amino acid esters with marked enantioselectivity. J Am Chem Soc 110: 1588-1595, 1988.

15 Kitamura I, Kochi M, Matsumoto Y, Ueoka R, Kuratsu J and Ushio Y: Intrathecal chemotherapy with 1,3-bis(2-chloroethyl)1-nitrosourea encapsulated into hybrid liposomes for meningeal gliomatosis: an experimental study. Cancer Res 56: 3986-3992, 1996.

16 Matsumoto Y, Kato T, Iseki S, Suzuki H, Iwahara M and Ueoka R: Remarkably enhanced inhibitory effects of hybrid liposomes on the growth of specific tumor cells. Bioorg Med Chem Lett 9: 1937-1940, 1999.

17 Matsumoto Y, Iwamoto Y, Matsushita T and Ueoka R: Novel mechanism of hybrid liposomes-induced apoptosis in human tumor cells. Int J Cancer 115: 377-382, 2005.

18 Komizu Y, Nakata S, Goto K, Matsumoto Y and Ueoka R: Membrane-targeted nanotherapy with hybrid liposomes for tumor cells leading to apoptosis. ACS Med Chem Lett 2: 275279, 2011.

19 Ichihara H, Ueno J, Umebayashi M, Matsumoto Y and Ueoka R: Chemotherapy with hybrid liposomes for acute lymphatic leukemia leading to apoptosis in vivo. Int J Pharm 406: 173-178, 2011. 
20 Ichihara H, Hino M, Umebayashi M, Matsumoto Y, Ueoka R: Intravenous injection of hybrid liposomes suppresses the liver metastases in xenograft mouse models of colorectal cancer in vivo. Eur J Med Chem 57: 143-148, 2012.

21 Ichihara H, Nakagawa S, Matsuoka Y, Yoshida K, Matsumoto Y, Ueoka R: Nanotherapy with hybrid liposomes for colorectal cancer along with apoptosis in vitro and in vivo. Anticancer Res 34: 4701-4708, 2014.

22 Ichihara H, Nagami H, Kiyokawa T, Matsumoto Y and Ueoka R: Chemotherapy using hybrid liposomes along with induction of apoptosis. Anticancer Res 28: 1187-1196, 2008.

23 Ichihara H, Okumura M and Matsumoto Y: Therapeutic effects of hybrid liposomes against xenograft mouse model of colorectal cancer in vivo due to long-term accumulation. Anticancer Res 36: 5875-5882, 2016.

24 Hiratsuka, M, Senoo T, Kimoto T and Namba M: An improved short-term culture method for human mammary epithelial cells. Gann 73: 124-128, 1982.

25 Smith HS, Lan S, Ceriani R, Hackett J and Stampfer MR: Clonal proliferation of cultured non-malignant and malignant human breast epithelia. Cancer Res 41: 4637-4643, 1981.

26 Liebes LF, Pelle E, Zucker-Franklin D and Silber R: Comparison of lipid composition and 1,6-diphenyl-1,3,5-hexatriene fluorescence polarization measurements of hairy cells with monocytes and lymphocytes from normal subjects and patients with chronic lymphocytic leukemia. Cancer Res 41: 4050-4056, 1981.

27 Komizu Y, Matsumoto Y and Ueoka R: Membrane targeted chemotherapy with hybrid liposomes for colon tumor cells leading to apoptosis. Bioorg Med Chem Lett 16: 6131-6134, 2006.

28 Ono A, Hattori S, Kariya R, Iwanaga S, Taura M, Harada H, Suzu S and Okada S: Comparative study of human hematopoietic cell engraftment into $\mathrm{BALB} / \mathrm{c}$ and $\mathrm{C} 57 \mathrm{BL} / 6$ strain of rag2/jak3 double-deficient mice. J Biomed Biotechnol 2011: 539748-1-6, 2011.
29 Inaba M, Sato S, Yamori T, Tashiro T, Ohnishi Y, Maruo K, Ueyama $\mathrm{Y}$ and Tsuruo $\mathrm{T}$ : Anticancer activities of orally administered menogaril against human stomach and breast cancers implanted in mude mice. Anticancer Res 12: 1953-1956, 1992.

30 Banciu M, Metselaar JM, Schiffelers RM and Storm G: Antitumor activity of liposomal prednisolone phosphate depends on the presence of functional tumor-associated macrophages in tumor tissue. Neoplasia 10: 108-117, 2008.

31 Okumura $\mathrm{M}$, Ichihara $\mathrm{H}$ and Matsumoto $\mathrm{Y}$ : Hybrid liposomes showing enhanced accumulation in tumors as theranostic agents in the orthotopic graft model mouse of colorectal cancer. Drug Deliv 25: 1192-1199, 2018.

32 Allen TM, Hansen C, Martin F, Redemann C and Yau-Young A: Liposomes containing synthetic lipid derivatives of poly(ethylene glycol) show prolonged circulation half-lives in vivo. Biochim Biophys Acta 1066: 29-36, 1991.

33 Papahadjopoulos D, Poste G and Schaeffer BE: Fusion of mammalian cells by unilamellar lipid vesicles: inflluence of lipid surface charge, fluidity and cholesterol. Biochim Biophys Acta 323: 23-42, 1973.

34 Sok M, Sentjurc $M$ and Schara M: Membrane fluidity characteristics of human lung cancer. Cancer Lett 139: 215-220, 1999.

35 Komizu Y, Ueoka H and Ueoka R: Selective accumulation and growth inhibition of hybrid liposomes to human hepatocellular carcinoma cells in relation to fluidity of plasma membranes. Biochem Biophys Res Commun 418: 81-86, 2012.
Received August 12, 2018

Revised September 3, 2018

Accepted September 5, 2018 